\title{
○ẹmetáa
}

\section{Mediação da cultura e da informação na Fundação Casa de José Américo}

\author{
Ana Claudia Medeiros de Sousa \\ Doutora; Universidade Federal da Bahia, Salvador, BA, Brasil \\ ana.violista@gmail.com \\ Raquel do Rosário Santos \\ Doutora; Universidade Federal da Bahia, Salvador, BA, Brasil \\ quelrosario@gmail.com \\ Andrea Medeiros de Sousa Maia \\ Bacharela; Fundação Casa de José Américo, João Pessoa, PB, Brasil \\ andreamedeirosbib@gmail.com
}

\begin{abstract}
Resumo: A mediação cultural e a mediação da informação promovem a disseminação e a apropriação da informação que permeia a esfera social, além de favorecer o acesso à memória e, ao mesmo tempo, potencializar o reconhecimento dos sentimentos de pertencimento aos ambientes e aos grupos sociais. Nesse contexto, esta pesquisa teve o objetivo de analisar as ações realizadas na Fundação Casa de José Américo, categorizá-las à luz do conceito de mediação da informação, cunhado por Almeida Júnior, e identificar os indícios de mediação cultural que favorecem o fortalecimento identitário e memorialístico do povo paraibano. Os referenciais teóricos e empíricos foram baseados nos aspectos conceituais de mediação cultural, mediação da informação, memória e identidade. Quanto à metodologia da pesquisa, a qual é de natureza descritiva, empregou-se o método do estudo de caso, tendo como objeto de investigação a Fundação Casa José Américo. Para coletar os dados, foi adotada a técnica de aplicação de questionário com os profissionais que atuam nos ambientes de informação da Instituição. Após analisar os dados coletados, constatou-se que a maioria dos participantes se reconhece como mediador da informação desenvolve ações diretas e indiretas de maneira consciente e alcança certa interferência no processo de mediação cultural, uma vez que favorece o reconhecimento e o fortalecimento dos traços memorialísticos e identitários do povo paraibano.
\end{abstract}

Palavras-chave: Mediação cultural. Mediação da informação. Memória. Identidade.

\section{Introdução}

As instituições de memória são as responsáveis por salvaguardar documentos considerados significativos para a constituição da memória e a identidade de seus produtores. Os arquivos, as bibliotecas, os museus e os centros de 
documentação custodiam, preservam e disseminam recursos informacionais que transparecem as práticas socioculturais de indivíduos e grupos sociais de maneira que as informações possibilitam o acesso ao passado e a compreensão do presente e apontam perspectivas futuras.

Entre as atividades inerentes às instituições de memória, estão as de tratamento, organização e disseminação dos recursos informacionais. Contudo, os agentes mediadores devem compreender o valor cultural desses recursos, que são representativos para fortalecer o sentimento de pertença de indivíduos e grupos sociais produtores. Nesse contexto, é válido ressaltar que são essenciais ações de mediação cultural que favoreçam a formação de sujeitos no que tange ao entendimento da constituição e da trajetória dos bens culturais, da necessidade de preservá-los e da disseminação do seu valor como um bem coletivo.

O mediador da informação deve atuar em uma perspectiva proativa e possibilitar, por meio dos dispositivos culturais e informacionais, sua transformação e dos demais sujeitos sociais. Nesse sentido, as mediações da informação e da cultura possibilitam que os sujeitos se apropriem das informações que permeiam a esfera social e, ao mesmo tempo, potencializam o reconhecimento dos sentimentos de pertencimento aos ambientes e aos grupos sociais.

Considerando a importância dos temas "mediação cultural" e "mediação da informação" e por reconhecer a inter-relação entre eles, este estudo teve o objetivo de analisar as ações realizadas na Fundação Casa de José Américo e categorizá-las à luz do conceito de mediação da informação, cunhado por Almeida Júnior, além de identificar os indícios de mediação cultural que favorecem o fortalecimento identitário e memorialístico do povo paraibano. Para isso, por meio da técnica de aplicação de questionário aos profissionais vinculados à Fundação Casa de José Américo, que atuam no arquivo, na biblioteca e no museu da instituição, foram analisados os ambientes informacionais, as atividades realizadas pelos mediadores e sua formação e a percepção de seu papel como mediadores da cultura e da informação. 
Quanto aos resultados sobre os elementos que integram o conceito formulado por Almeida Júnior (2015), o estudo indicou que parte significativa dos participantes se reconhece como mediador da informação e desenvolve ações diretas e indiretas, portanto, é consciente de sua atuação quanto às necessidades informacionais dos usuários e também interfere no processo de mediação cultural, quando favorece o reconhecimento e o fortalecimento dos traços memorialísticos e identitários do povo paraibano.

\section{Mediação da cultura e da informação para constituição da memória e da identidade}

As instituições de memória, como arquivos, museus, bibliotecas e centros de documentação, acumulam e preservam diversos tipos de documentos que materializam vestígios de práticas socioculturais, porque atribui-se valor para alguns documentos e eles são reconhecidos como bens patrimoniais. Nesse ponto, é válido ressaltar a importância das ações diretas e indiretas de mediação da informação e da cultura para disseminar os conteúdos registrados em documentos considerados bens patrimoniais, uma vez que o acesso ao patrimônio cultural é essencial para o desenvolvimento dos indivíduos e de seu meio.

Os bens patrimoniais são referenciais de memória e de identidade, estão presentes no contexto sociocultural em que os indivíduos e os grupos se reconhecem, como saberes, expressões, lugares, celebrações e monumentos que resultam na relação do sujeito com o mundo. Além do reconhecimento social seja do indivíduo ou do coletivo -, esses bens são validados pelo Estado. Gonçalves (2005, p. 19) compreende que

[...] um patrimônio não depende apenas da vontade e decisão políticas de uma agência de Estado. Nem depende exclusivamente de uma atividade consciente e deliberada de indivíduos e grupos. Os objetos que compõem um patrimônio precisam encontrar ressonância junto a seu público.

A partir dessa reflexão apresentada por Gonçalves (2005), entende-se que os bens patrimoniais devem transparecer os aspectos constituintes da 
identidade de seus produtores. Isso requer ações de mediação cultural que favoreçam a formação de sujeitos que entendam a constituição e a trajetória dos bens culturais e a necessidade de preservá-los e de disseminar seu valor como um bem coletivo.

A mediação cultural “[...] visa apresentar e tornar conhecidas as diferentes manifestações culturais presentes na esfera social" (SILVA; SANTOS NETO, 2017, p. 31), ou seja, potencializa os traços culturais que permeiam o contexto social em que indivíduos e grupos estão inseridos e contribui para que o sujeito conheça e/ou ressignifique os diferentes elementos socioculturais presentes na esfera social.

Nesse contexto da mediação cultural, quando o agente mediador promove ações que tornem conhecidos os bens culturais, deve considerar as especificidades dos espaços sociais para viabilizar a apropriação da informação e fortalecer a memória e a identidade de indivíduos e de grupos. Para tanto, será necessário negociar sentidos e estabelecer comunicabilidade, pois

O mediador cultural é um protagonista cultural, que atua negociando sentidos, realizando tarefas e propondo ações que viabilizam a apropriação e o protagonismo cultural dele e de indivíduos, grupos e coletividades. Seus fazeres compreendem certamente planejamento e gerenciamento de projetos culturais, mas baseados na dialogia com outros protagonistas, para que se estabeleça a comunicabilidade entre acervos, tangíveis e intangíveis, repertórios humanos e os protagonistas da cultura. (LIMA; PERROTTI, 2017, p. 19).

Nessa perspectiva, o agente mediador é um sujeito proativo que, por meio da negociação e da dialogia, possibilita a própria transformação e a dos demais indivíduos, ao promover a disseminação e a apropriação da informação presente na esfera social. Assim, a mediação da informação e a da cultura possibilita o acesso à memória e gera sentimentos de pertencimento e de continuidade.

De acordo com Pollak (1992, p. 5),

[...] a memória é um elemento constituinte do sentimento de identidade, tanto individual como coletiva, na medida em que é também um fator extremamente importante do sentimento de continuidade e de coerência de uma pessoa ou de um grupo em sua reconstrução de si. 
Nessa conjuntura, a produção da informação expressa construções identitárias, descortina traços de memória e é capaz de revelar a estrutura sociocultural de quem a produziu. A relação entre a informação e a memória se constitui

[...] na medida em que determinado elenco de informações que se referem ao passado de um grupo são reunidas e relacionadas entre si, como forma de dar um sentido de compartilhamento de passados, constantemente construídos e reinterpretados. Assim pode-se exemplificar a relação entre a informação e a memória na multiplicidade de suportes que a informação pode assumir, no seu processo de representação através da cultura material, expressos como documentos e monumentos. (AZEVEDO NETTO, 2007, p. 14-15).

Os documentos registram acontecimentos que revelam o passado, justificam o presente e orientam o futuro. Dodebei (1997, p. 44) compreende que "[...] como o homem habita o espaço cultural que ele próprio cria e transforma continuamente, necessita utilizar o passado como marco referencial e auto-identificador." Por isso, é importante preservar os artefatos utilizados pelos indivíduos que registram informações e delineiam suas práticas cotidianas.

Ainda de acordo com Dodebei (1997, p. 44), “[...] a necessidade de memória não passa apenas pela identificação do ser como vivente, mas revela-se como uma transcendência à vida terrena. Uma vontade supra objetiva de ligação a elos do passado que subsistirão no futuro, garantindo, assim, a eternidade." Dessa maneira, o indivíduo cria expressões e adquire saberes e artefatos materiais que ligam o passado e o presente com a intenção de preservar a memória e a identidade de si e do outro, além de informar para as gerações futuras sobre essas práticas. Assim, pode-se afirmar que as práticas informacionais estão inter-relacionadas aos aspectos identitários e podem também evocar os traços memorialísticos de seus produtores.

Ao analisar os enunciados registrados em um documento, o sentido de teor informacional será determinado pelo objetivo da apreciação, e não pela função/ação que o gerou, pois o documento é produzido em meio a uma ação para cumprir inicialmente uma função, e só depois é que lhe será atribuído o valor histórico. Sobre os documentos que hoje são considerados históricos: 
[...] foram os administrativos de ontem, e os documentos administrativo de hoje serão os documentos históricos de amanhã. Mesmo os documentos históricos de hoje podem torna-se novamente administrativos amanhã, por diversas circunstâncias, devido a sua utilização. Apesar de os arquivos serem conservados primeiramente para fins administrativos, constituem base fundamental para a história, não apenas do órgão a que pertencem, mas também do povo e suas relações sociais e econômicas (PAES, 2009, p. 121).

Nesse sentido, é relevante planejar e realizar ações diretas e indiretas de mediação da cultura e da informação que favoreçam a preservação, a organização e a disseminação dos dispositivos, que são carregados de valores informacionais e culturais. Além disso, eles assumem, em sua constituição e trajetória, o reconhecimento social, seja do indivíduo ou do coletivo e perpassam as barreiras temporais e geográficas, informando aos sujeitos e ressignificando seus olhares sobre a memória e a identidade sociais. Assim, no processo de intervenção da constituição e da formação dos sujeitos e de seus dispositivos culturais, sociais e informacionais, a mediação é sobremaneira relevante.

Em várias áreas do conhecimento, como a Religião, a Psicologia, o Direito, a Educação etc., que refletem, estudam e se apropriam do termo "mediação", ela própria é tratada embasando as reflexões e as ações de seus pesquisadores e profissionais, com o objetivo de fundamentar a ação consciente por parte dos referidos atores sociais. A mediação vem sendo refletida também no âmbito da Ciência da Informação, sendo conceituada por Almeida Júnior (2015, p. 15), para quem a mediação da informação é

[...] toda ação de interferência - realizada em um processo, por um profissional da informação e na ambiência de equipamentos informacionais - direta ou indireta; consciente ou inconsciente; singular ou plural; individual ou coletiva; visando a apropriação de informação que satisfaça, parcialmente e de maneira momentânea, uma necessidade informacional, gerando conflitos e novas necessidades informacionais.

A partir da reflexão realizada por Almeida Júnior (2015), percebe-se que a medição da informação tem o objetivo de apoiar o sujeito para que ele se aproprie da informação. Nesse contexto, além de auxiliar o acesso e o uso da informação, os profissionais da informação devem estimular o sujeito a se 
(trans)formar, a desenvolver competências em informação e a produzir conhecimentos que interfiram não só em seu crescimento, mas também na vida do outro e no contexto sociocultural em que ele está inserido. Para alcançar esse objetivo, os profissionais da informação desenvolvem ações que vão desde a organização até a disseminação e o apoio ao leitor. Almeida Júnior (2015) chama de ações diretas e indiretas de mediação da informação.

Ao interferir nesse processo, de maneira individual ou coletiva, o mediador auxilia os usuários a se apropriarem da informação e lhes possibilita uma mudança interna e externa por meio de suas ações diretas e indiretas de mediação da informação. Nesse sentido, a mediação pode ser realizada de maneira indireta, como, por exemplo, as atividades em que o mediador planeja, organiza e articula os dispositivos que devem apoiar o acesso à informação e seu uso. Por outro lado, realiza ações diretas de mediação da informação, em que existem interação e encontro entre os usuários e o mediador, ocorrendo de maneira direta e personalizada, como, por exemplo, as atividades realizadas no serviço de referência presencial ou digital.

Segundo Almeida Júnior (2015), as ações de mediação da informação ocorrem de maneira singular e/ou plural. Então, o mediador deve entender que cada sujeito tem sua singularidade, a qual o torna diferente em seus múltiplos aspectos, tanto devido ao seu conhecimento e à sua história de vida quanto ao comportamento e à relação que estabelece com outros sujeitos e com o meio. Para que as ações de mediação da informação sejam conscientes e efetivas, é preciso ter clareza sobre os dispositivos culturais e sociais que podem apoiar suas atividades e os métodos que podem ser adotados para favorecer essa aproximação.

Nesse processo, “[...] a melhor forma de construir qualquer tipo de mediação em torno dos diversos bens culturais que ganham valor de patrimônio representativo de alguma coletividade é, sem dúvidas, conhecendo a trajetória dos seus sentidos." (NOGUEIRA; RAMOS FILHO, 2020, p. 4). Então, o agente mediador precisa ter consciência do contexto em que os bens culturais e os dispositivos informacionais são produzidos e validados pelos sujeitos, ou seja, do sentido conferido a tais bens e dispositivos culturais e informacionais. Esse 
processo de conscientização poderá fundamentar suas ações mediadoras em uma perspectiva de representatividade individual ou coletiva.

A informação pode ser mediada por meio de diferentes ações, em distintos dispositivos informacionais, sociais e culturais, para que tais dispositivos sejam apropriados e ressignificados pelos sujeitos. Pieruccini (2007, p. 35) define o dispositivo como um "[...] signo, um mecanismo de intervenção sobre o real, que atua por meio de formas de organização estruturada, utilizando-se de recursos materiais, tecnológicos, simbólicos e relacionais, que atingem os comportamentos e as condutas afetivas, cognitivas e comunicativas dos indivíduos." Nesse sentido, arquivos, bibliotecas, museus e centros de documentação são dispositivos socioculturais que guardam, organizam e disseminam outros dispositivos elaborados pela humanidade na tentativa de entender, explicar e se comunicar com o meio. Esses dispositivos apoiam os sujeitos sociais em suas necessidades informacionais e na produção de novos conhecimentos.

Gomes $(2014,2016,2017)$ refere que a efetividade da mediação da informação é consequência do alcance de cinco dimensões, que podem ser reconhecidas como dialógica, estética, formativa, ética e política. Gomes (2014, 2016, 2017) sustenta que, quando se alcançam as cinco dimensões de maneira articulada, a ação mediadora contribui com a apropriação da informação, por meio da qual o protagonismo social se desenvolve. Para a autora, a tomada de posição em uma situação está diretamente relacionada à apropriação da informação pelos sujeitos sociais, a qual é uma base fundamental no processo de domínio do conhecimento, da conscientização e do surgimento do sujeito protagonista.

Quando alcançam a dimensão dialógica, os sujeitos adquirem a consciência de propiciar os espaços de interação e de se apropriar deles, o que permite a crítica e a criatividade, que conferem desejo e prazer aos sujeitos em vivenciar e realizar as ações de mediação da informação. Nessa situação, alcançam a dimensão estética.

A dimensão formativa tanto se refere ao mediador quanto aos usuários, pois se caracteriza pelo desenvolvimento e pelo surgimento de novas 
competências, que podem estar implícitas na ação de mediar, como, por exemplo, a escuta sensível, a realização de diálogo e o acolhimento, características essenciais ao processo de mediação. Conforme Gomes (2016), os sujeitos só poderão se apropriar da informação por meio da interferência consciente e competente do mediador para evitar manipulação, portanto, se alcançarem a dimensão ética. Por fim, ao se conscientizar de sua condição de protagonista social, o mediador da informação atua na perspectiva da dimensão política que, segundo Gomes (2016, p. 101), é “[...] a potência transformadora que pode decorrer da ação mediadora [...] que vindica do agente mediador uma tomada de posição acerca do papel social." Assim, é preciso que os mediadores da informação atuem em uma perspectiva consciente, sejam protagonistas e apoiem outras pessoas para que possam atuar na tomada de posição acerca da própria história.

\section{Trajetória metodológica}

Este estudo caracteriza-se como "descritivo" pois, segundo Gil (2010, p. 27), ele tem "[...] o objetivo de descrever as características de determinada população ou fenômeno ou, então, estabelecer relações entre variáveis.”. Quanto aos procedimentos, trata-se de um estudo de caso, o qual, para Alves (2007, p. 58), é “[...] um estudo em profundidade [...] de uns poucos objetos visando obter o máximo de informações que permitam o amplo conhecimento [para o pesquisador] [...]". Nesse sentido, busca-se evidenciar as especificidades da mediação cultural e da informação no âmbito da Fundação Casa de José Américo.

Dessa maneira, o objetivo desta pesquisa foi analisar as ações realizadas na Fundação Casa de José Américo, categorizá-las à luz do conceito de mediação da informação, cunhado por Almeida Júnior (2015), e identificar os indícios de mediação cultural que favorecem o fortalecimento identitário e memorialístico do povo paraibano. A fim de alcançar esse objetivo, foi aplicado um questionário para 16 profissionais que atuam na Fundação Casa de José Américo, via internet, entre os dias 22 de março e 06 de abril de 2020. Obteve- 
se resposta de nove profissionais. Esse instrumento de coleta de dados foi composto de 13 questões, distribuídas em três categorias, reconhecidas como (1) perfil do informante, (2) ambiência e repertório informacional e (3) atuação e formação dos mediadores.

Para analisar os dados, foram adotadas a abordagem quantitativa, para mensurar os dados passíveis de quantificação, e a qualitativa, que auxiliou a interpretação das respostas dissertativas elaboradas pelos participantes da pesquisa. Para os resultados obtidos a partir dos questionários, adotou-se a análise de conteúdo, que, segundo Bardin (2011), é considerada um conjunto de técnicas de análise das comunicações, obtidas por meio de procedimentos sistemáticos e objetivos de descrição do conteúdo das mensagens, indicadores que permitam inferir conhecimentos relativos às condições de produção/recepção dessas mensagens. Bardin (2011) afirma que são três as fases que integram a análise de conteúdo e que podem ser adaptadas da seguinte maneira:

a) pré-análise - mapeamento do perfil dos informantes, de modo a identificar a área de formação; escolaridade; cargo/ função; setores e tempo de serviço na instituição; ambiência e repertório informacional do arquivo, da biblioteca e do museu; e atuação e formação dos mediadores;

b) exploração do material - corresponde à leitura, à primeira análise e à seleção dos dados obtidos com a aplicação do questionário;

c) tratamento dos resultados, inferência e interpretação - elaboração das ilustrações para apresentar e interpretar as respostas obtidas.

Foi empregada a técnica de categorização que, segundo Bardin (2011), está relacionada à investigação do que cada elemento tem em comum com o outro, e o que vai permitir o seu agrupamento é a parte comum entre eles. Assim, as respostas dos participantes foram selecionadas por sua semelhança argumentativa que aglutinam aspectos comuns em outras respostas.

Conforme exposto, o campo empírico de pesquisa foi a Fundação Casa de José Américo, que funciona na antiga residência do escritor paraibano, José Américo de Almeida. A Fundação foi criada em 1980, por meio do Decreto-lei $\mathrm{n}^{\mathrm{o}}$ 4.195, do Governo do estado da Paraíba, e dedica-se a promover a obra de 
José Américo, divulgando o museu, a biblioteca e o arquivo que preservam sua obra. A intenção é torna-los acessíveis para uso e consulta públicos. Busca promover, ainda, ações que visam difundir a cultura e a pesquisa relacionadas à vida e à obra de José Américo, além de aspectos pertinentes ao regionalismo nordestino (FCJA, [20--?]).

A Fundação Casa de José Américo tem custodiado, além dos recursos informacionais advindos da vida e da obra do escritor, outros acervos documentais considerados representativos para a cultura paraibana, como o acervo de cultura popular e os arquivos dos Governadores da Paraíba e de personalidades paraibanas. Esses aspectos, que especificam a instituição que é o meio de investigação deste estudo, também justificam, devido à sua importância, a adoção e a realização de uma análise sobre as práticas de mediação da cultura e da informação abordadas nesta pesquisa.

\section{Apresentação e análise dos resultados}

Para atingir o objetivo deste estudo, foi aplicado um questionário para os profissionais que atuam na Fundação Casa de José Américo, cujo instrumento foi dividido em três categorias: perfil do informante; ambiência e repertório informacional; atuação e formação dos mediadores.

Quanto ao perfil dos informantes, no que se refere à sua formação educacional, entre os nove respondentes, quatro têm Graduação; três, Especialização; um, Mestrado e um, Doutorado. Os que participaram da pesquisa têm buscado ampliar seu conhecimento, ingressando em cursos de pósgraduação. Pode-se considerar que os participantes têm alcançado a dimensão formativa que é defendida por Gomes (2014, 2016, 2017), porquanto aprimoram suas competências por meio dos cursos, o que também poderá refletir na formação dos usuários, já que, além do conhecimento prático, haverá uma fundamentação com base no arcabouço teórico.

No que diz respeito ao cargo/função que os respondentes ocupam, conforme o Quadro 1, cinco respondentes atuam na gestão; um é auxiliar na Biblioteca, dois são arquivistas e um é monitor. 
Quadro 1 - Informações sobre o perfil dos informantes

\begin{tabular}{|c|c|c|c|c|}
\hline $\begin{array}{l}\text { Código dos } \\
\text { respondentes }\end{array}$ & $\begin{array}{l}\text { Perfil dos } \\
\text { informantes }\end{array}$ & Cargo/função & Setores & $\begin{array}{c}\text { Tempo de } \\
\text { serviço }\end{array}$ \\
\hline Respondente 1 & $\begin{array}{l}\text { Graduação em } \\
\text { Pedagogia }\end{array}$ & Monitor & Museu & $\begin{array}{c}2 \text { anos e } 6 \\
\text { meses }\end{array}$ \\
\hline Respondente 2 & $\begin{array}{l}\text { Graduação em } \\
\text { Jornalismo. } \\
\text { Especialização }\end{array}$ & $\begin{array}{l}\text { Chefe do Núcleo de } \\
\text { Processamento de } \\
\text { Documentos } \\
\text { Digitais da FCJA }\end{array}$ & $\begin{array}{c}\text { Setor de } \\
\text { Documentação e } \\
\text { Arquivo }\end{array}$ & $\begin{array}{c}3 \text { anos e } 8 \\
\text { meses }\end{array}$ \\
\hline Respondente 3 & $\begin{array}{l}\text { Graduação em } \\
\text { Arquivologia }\end{array}$ & Arquivista & $\begin{array}{c}\text { Setor de } \\
\text { Documentação e } \\
\text { Arquivo }\end{array}$ & 4 anos \\
\hline Respondente 4 & $\begin{array}{l}\text { Geógrafo e } \\
\text { especialista }\end{array}$ & $\begin{array}{l}\text { Auxiliar de } \\
\text { biblioteca }\end{array}$ & Biblioteca & 34 anos \\
\hline Respondente 5 & $\begin{array}{l}\text { Doutorado em } \\
\text { História }\end{array}$ & Gerente executiva & $\begin{array}{c}\text { Setor de } \\
\text { Documentação e } \\
\text { Arquivo }\end{array}$ & 3 anos \\
\hline Respondente 6 & $\begin{array}{c}\text { Bibliotecária e } \\
\text { Mestra }\end{array}$ & Gerente executiva & Biblioteca & 11 anos \\
\hline Respondente 7 & Especialização & Chefe de protocolo & $\begin{array}{c}\text { Setor de } \\
\text { Documentação e } \\
\text { Arquivo }\end{array}$ & $\begin{array}{c}1 \text { ano e } 3 \\
\text { meses }\end{array}$ \\
\hline Respondente 8 & $\begin{array}{l}\text { Graduação em } \\
\text { Arquivologia }\end{array}$ & Arquivista & $\begin{array}{l}\text { Departamento de } \\
\text { Doc. e Arquivo - } \\
\text { Arquivo dos } \\
\text { Governadores. }\end{array}$ & 3 anos \\
\hline Respondente 9 & $\begin{array}{l}\text { Graduação em } \\
\text { Arquivologia }\end{array}$ & $\begin{array}{c}\text { Gerente Operacional } \\
\text { do Arquivo dos } \\
\text { Governadores }\end{array}$ & $\begin{array}{c}\text { Gerência Executiva } \\
\text { de Documentação e } \\
\text { Arquivo }\end{array}$ & 4 anos \\
\hline
\end{tabular}

Fonte: Dados da pesquisa.

Quanto ao tempo de serviço dos respondentes, de acordo com o Quadro 1, dois participantes da pesquisa têm mais de dez anos de prestação de serviços na instituição, ao passo que outras cinco pessoas têm entre três e quatro anos e dois têm menos tempo de vínculo com a Instituição - um, um ano e três meses, e o outro, dois anos e seis meses. Esses dados indicam que todos os respondentes já possuem mais de um ano na Fundação Casa de José Américo, tendo conhecimento sobre a Instituição e experiências relativas ao desenvolvimento de suas atividades e funções. 


\section{1 Ambiência e repertório informacional do arquivo, da biblioteca e do museu}

No questionário, também se levantaram informações sobre a ambiência e o repertório informacional da Fundação Casa de José Américo. Inicialmente, foi perguntado quais os gêneros e os tipos documentais disponibilizados para os usuários no setor em que os participantes trabalham. O Respondente 1, que atua no museu, citou que existem os gêneros e suas respectivas tipologias documentais, como textuais (discursos, relatórios, correspondência, jornais etc.), iconográficos (fotografias), audiovisuais (vídeos e filmes) e bitridimensionais (comendas, medalhas e objetos).

Seis respondentes que trabalham nos arquivos citaram gêneros e tipos documentais, como textuais (ofícios, memorandos, discursos etc.), iconográficos (fotografias), cartográficos (mapas, plantas etc.), audiovisuais (vídeos, filmes), sonoros (vinis, fitas-cassete e CD), bitridimensionais (comendas, medalhas e objetos) e digitais (documentos textuais, iconográficos, entre outros, digitalizados).

Já os dois respondentes que trabalham na biblioteca citaram os gêneros textuais, iconográficos, audiovisuais, tridimensionais e alguns digitais. Quanto aos tipos, mencionaram livros, catálogos, relatórios, boletins, plaquetas, almanaques, anais, anuários, atlas, periódicos, folhetos, jornais literários e informativos, CD, DVD e peças artesanais.

Há uma diversidade de repertórios informacionais referentes ao gênero e ao tipo documental. Assim, os respondentes poderão fazer diferentes atividades que, conforme defende Almeida Júnior (2015), sejam, em uma perspectiva individual e singular, direcionadas às necessidades específicas do sujeito e a ações coletivas e plurais. Elas visam alcançar os objetivos propostos por cada setor, em que os sujeitos, como uma comunidade, sintam que suas necessidades informacionais e seus anseios estão sendo considerados, para que possam se apropriar da informação e do ambiente informacional em que esses documentos estão sendo mediados.

Com o objetivo de saber qual a percepção dos respondentes sobre a ambiência, eles foram questionados como os usuários se sentem quando visitam 
a Instituição e utilizam os serviços e os produtos no setor em que eles trabalham. Os nove respondentes afirmaram que os usuários se sentem confortáveis. Dentre as respostas apresentadas, foram selecionadas as mais representativas, visto que tais argumentos aqui apresentados contemplam as respostas dos demais participantes da pesquisa.

Quadro 2 - Percepção dos agentes mediadores sobre a identificação do conforto atribuído pelos usuários quanto ao uso dos espaços e dos serviços

\begin{tabular}{|l|l|}
\hline Respondentes & \multicolumn{1}{|c|}{ Comentários } \\
\hline Respondente 3 & $\begin{array}{l}\text { Porque, no decorrer da visita guiada, recebemos alguns elogios a respeito do } \\
\text { acervo e da forma como apresentamos, e, muitas vezes, o visitante volta com } \\
\text { outras pessoas. Já na pesquisa ao final de todo trabalho concluído, o } \\
\text { pesquisador vem cordialmente agradecer o colaborador da instituição pela ajuda } \\
\text { no acesso à informação. }\end{array}$ \\
\hline Respondente 5 & $\begin{array}{l}\text { Tendo em vista que a FCJA e seu Arquivo se destacam no estado da Paraíba } \\
\text { pela organização do arquivo, equipe capacitada e ambiente adequado para o } \\
\text { acervo e atendimento ao usuário. O que não significa ser perfeitamente } \\
\text { confortável, pois ainda se precisa melhorar em alguns_aspectos, a exemplo da } \\
\text { ampliação das formas de acesso remoto ao acervo pelo usuário, que ainda é } \\
\text { muito restrito. }\end{array}$ \\
\hline Respondente 6 & $\begin{array}{l}\text { Temos uma equipe formada com preparo acadêmico e profundo conhecimento } \\
\text { do acervo bibliográfico da FCJA, disponibilizado para a pesquisa, onde } \\
\text { buscamos a informação solicitada nos registros eletrônicos, construído a partir } \\
\text { das informações extraídas das coleções que formam o acervo da FCJA. } \\
\text { Fazemos também, a busca de forma sistêmica, utilizando outras fontes internas } \\
\text { das Unidades de Informação (Museu e Arquivo) da FCJA. E ainda, em } \\
\text { pesquisas mais exaustivas, buscamos informações externas em outras } \\
\text { bibliotecas, com o intuito de atender ao usuário com o maior grau de precisão, } \\
\text { para que nosso atendimento seja mais próximo da eficiência e eficácia que o } \\
\text { usuário e sua pesquisa demandam, elevando o seu grau de satisfação. }\end{array}$ \\
\hline
\end{tabular}

Fonte: Dados da pesquisa.

A fala do Respondente 3 demonstra que os usuários explicitam sua satisfação quanto ao ambiente físico, ao conteúdo e às ações mediadoras que são desenvolvidas. Vale destacar a função de agente mediador que muitos usuários passam a desempenhar. Isso se confirma na fala do Respondente 3, segundo o qual os usuários, além de voltar ao ambiente, levam outros sujeitos. Essa ação demonstra que esses usuários reconheceram a importância desse ambiente para sua formação e atuam como multiplicadores, para que outros também possam ter acesso às informações. Assim, pode-se considerar que tanto o agente 
mediador quanto os usuários são protagonistas quando transformam a si e aos outros, como defendem Lima e Perrotti (2017).

Quanto ao comentário do Respondente 5, apesar de reconhecer as qualidades da organização do acervo e do ambiente e a qualificação dos profissionais, sugere mudanças. Ele apresenta uma postura de agente mediador que não se conforma com o que lhe é dado e o que foi alcançado, pois carrega um olhar crítico e busca atender efetivamente às demandas indicadas pelos usuários e ressignificar constantemente sua atuação e o ambiente de mediação.

O Respondente 6 ratifica os dados que foram identificados no Quadro 1, ao observar uma conduta de formação continuada dos participantes da pesquisa, e destaca uma percepção de sistema de informação ao atuar de maneira conjunta com outros setores da Fundação. Além disso, quando necessário, de forma proativa, busca uma interlocução com outras instituições, a fim de atender às demandas informacionais dos usuários. Agindo dessa maneira, os usuários também poderão entender que as unidades informacionais são redes colaborativas que se articulam de maneira integrada e têm a informação como um elemento comum. Nesse contexto, a mediação dos distintos documentos está implícita e explícita na atuação dos agentes mediadores, na forma como atuam, reconhecem-se e entendem sua participação no meio e na vida dos outros sujeitos.

\subsection{Atuação e formação dos mediadores}

No que diz respeito à atuação e à formação dos mediadores, com base no conceito de Almeida Júnior (2015) apresentado no questionário, perguntou-se aos participantes da pesquisa se eles se consideram mediadores da informação. Os nove respondentes afirmaram positivamente. No Quadro 3, algumas justificativas foram selecionadas com a intenção de representar os argumentos utilizados pelos participantes, visto que as demais respostas apresentavam elementos discursivos semelhantes.

Em sua fala, o Respondente 1 menciona afetividade ao descrever suas atribuições, no qual se reconhece como mediador. Já o Respondente 2 afirma que é mediador da informação por proporcionar além do acesso à informação, 
materializada no acervo, a autonomia do usuário, que passa a compreender a organização do acervo. Dessa maneira, além da apropriação da informação, existe a apropriação do ambiente informacional. Assim, ao mediar de maneira consciente e humanística, o mediador possibilita a adoção técnica e metodológica que fundamenta suas atividades e considera os sentimentos dos usuários e os seus próprios.

Quadro 3 - Percepção dos profissionais como mediadores da informação

\begin{tabular}{|c|c|}
\hline Respondentes & Comentários \\
\hline Respondente 1 & $\begin{array}{l}\text { Sim, pois essa é a função que exerço no museu e a desempenho com muito } \\
\text { esmero. }\end{array}$ \\
\hline Respondente 2 & $\begin{array}{l}\text { Sim, eu me considero. Uma vez que, passo para os visitantes um pouco da } \\
\text { história dos titulares dos arquivos, bem como, um pouco de como os acervos } \\
\text { foram organizados - na minha fala, fica então impressa, um pouco do contexto } \\
\text { histórico e social de nossa região. }\end{array}$ \\
\hline Respondente 3 & $\begin{array}{l}\text { Sim, a partir do momento que conduzo o usuário em uma visita e apresento cada } \\
\text { acervo ali disponível, por mais que ele conheça a história de vida do titular, na } \\
\text { minha apresentação alguns detalhes irão acrescentar as informações que já } \\
\text { existiam, tanto sobre o titular como também sobre as técnicas arquivísticas pelas } \\
\text { quais os acervos foram organizados e disponibilizados. }\end{array}$ \\
\hline Respondente 6 & $\begin{array}{l}\text { Sim. Dentre os serviços e produtos que buscamos oferecer para os usuários, } \\
\text { levamos sempre em consideração: } \\
\text { a missão da instituição (FCJA), a qual, a biblioteca encontra-se vinculada, } \\
\text { pesquisando, preservando e divulgando o seu patrono José Américo de Almeida } \\
\text { e a cultura paraibana; } \\
\text { o plano estratégico com as ações e metas determinadas pelo Governo do Estado } \\
\text { da Paraíba para a Cultura, encaminhadas através da Secretaria de Estado da } \\
\text { Cultura, são absorvidos pela equipe da FCJA, no desenvolvimento de seu plano } \\
\text { de ação e projetos específicos; } \\
\text { a necessidade de informação e pesquisa demandadas pela sociedade em geral; e, } \\
\text { e a missão informacional, cultural e social que a profissão de bibliotecário exige } \\
\text { do profissional que exerce o cargo de gestor da informação. } \\
\text { Então, elaborar e apresentar projetos com ideias inovadoras, que inclua a cultura } \\
\text { popular, de movimentos culturais que vem das ruas, procurando romper com a } \\
\text { ideia engessada de que à FCJA representa a cultura assimilada das Instituições } \\
\text { Acadêmicas ou imposta pelo Governo, direcionadas para a classe } \\
\text { intelectualizada e/ou abastada financeiramente. Procuramos introduzir um } \\
\text { conhecimento cultural nas duas vias (do popular ao clássico e do clássico para o } \\
\text { popular). }\end{array}$ \\
\hline Respondente 9 & $\begin{array}{l}\text { Sim, me considero uma mediadora da informação. É sabido que a mediação da } \\
\text { informação é de suma importância na função do arquivista e está presente nas } \\
\text { atividades diárias do profissional de arquivo. Somos uma espécie de } \\
\text { facilitadores no acesso ao documento, visto que, no processo de organização, } \\
\text { tratamento e registro da documentação estamos também proporcionando } \\
\text { melhores condições de busca, acesso e uso da informação registrada no } \\
\text { documento. Nesse sentido, auxiliamos na consulta, na busca e recuperação da }\end{array}$ \\
\hline
\end{tabular}



construção desse conhecimento.

Fonte: Dados da pesquisa.

$\mathrm{Na}$ fala do Respondente 2, destaca-se a palavra 'pouco', que ele enfatiza em várias de suas atribuições e demonstra a humildade de reconhecer que sua ação integra um coletivo que auxilia os sujeitos no processo de formação. Esse dado é confirmado pelo Respondente 3, ao afirmar que, em sua apresentação, algumas novas informações agregarão valor e ampliarão o repertório do usuário. Constata-se e ratifica-se a necessidade de uma mediação da informação na perspectiva coletiva, em que tanto os mediadores quanto os usuários reconheçam a pluralidade das informações, dos documentos e dos ambientes de mediação.

Nessa perspectiva agregadora de conhecimentos, evidencia-se, na fala do Respondente 6, o que se defende neste trabalho: a convergência entre as mediações da cultura e da informação. Além do conhecimento registrado nos acervos dos ambientes informacionais e culturais, que foram avaliados e reconhecidos pelos sujeitos e pelas comunidades, devem ser considerados os saberes e os aspectos identitários e memorialísticos presentes em comunidades em que esses ambientes mediadores estão localizados. Assim, para que o mediador exerça com efetividade suas ações, ele deve considerar também o valor simbólico das estruturas documentais, institucionais e culturais.

Reitera-se que no processo de mediação da informação, ao considerar o valor simbólico e o sentimento de pertencimento, pode ocorrer uma inter-relação com a mediação cultural, em que o sujeito mediador age conscientemente, identifica e torna evidentes os vestígios identitários e memorialísticos dos ambientes e dos grupos sociais. Dessa forma, possibilita a (re)significação de tais elementos tanto pelos sujeitos vinculados a determinado espaço sociocultural quanto de outros que perpassam as fronteiras geográficas.

Em sua fala, o Respondente 6 dirige um olhar sensível para as distintas manifestações culturais presentes na esfera social, como defendem Silva e Santos Neto (2017), relacionadas a um processo de mediação consciente da 
informação e da cultura. Como a proposta da Fundação Casa de José Américo é subsidiar ações que potencializem a preservação dos elementos socioculturais da Paraíba e, quando abre espaço para a cultura popular da região, passa a salvaguardar os artefatos que transparecem o público paraibano, mostra uma consonância com os apontamentos de Gonçalves (2005) sobre o patrimônio como ressonância de seus produtores.

A fala do Respondente 9 ratifica o alcance das dimensões dialógica, estética, formativa, ética e política defendidas por Gomes (2014, 2016, 2017). A autoconsideração do participante como mediador da informação demonstra uma consciência da sua responsabilidade social no processo de interferência que apoia a formação e atuação dos usuários. Isso significa que a interação e o reconhecimento do outro podem fortalecer o sentimento de cumprimento de sua missão e de seus objetivos profissionais. Portanto, esse profissional passa a aprimorar seu fazer de maneira ética e assume uma ação protagonista. Assim, possibilitam que os usuários também encontrem nas unidades de informação um espaço de transformação de si e do meio.

A partir da percepção como mediadores da informação, os participantes da pesquisa foram questionados sobre quais as atividades diretas e indiretas de mediação da informação que realizam.

Quanto à ação direta de mediação da informação, o Respondente 2 indicou visitas guiadas com visitantes e com pesquisadores. Em complementação à fala do Respondente 2, o 5 referiu que realiza apresentação sobre os acervos, concede entrevistas e responde pelo Memorial da Democracia. Além de atividades diretas coletivas, são feitas atividades individuais para atender a necessidades específicas.

Quadro 4 - Ações diretas e indiretas de mediação da informação

\begin{tabular}{|l|l|}
\hline $\begin{array}{l}\text { Comentários sobre ações diretas de mediação } \\
\text { da informação }\end{array}$ & $\begin{array}{l}\text { Comentários sobre ações indiretas de mediação da } \\
\text { informação }\end{array}$ \\
\hline $\begin{array}{l}\text { Visitas guiadas com os visitantes e e } \\
\text { pesquisadores (Respondente 2) }\end{array}$ & $\begin{array}{l}\text { As atividades predominantes são referentes ao } \\
\text { processamento técnico de documentos, como: } \\
\text { análise, separação e identificação das espécies e } \\
\text { tipologias documentais, higienização do acervo, } \\
\text { ordenação das séries e acondicionamento etc. } \\
\text { (Respondente 8) }\end{array}$ \\
\hline
\end{tabular}


Explanação sobre os acervos existentes no Arquivo. Concessão de entrevistas a pesquisadores sobre o acervo e o funcionamento do Arquivo. Atendimento direto aos documentos do Memorial da Democracia. (Respondente 5)
Idealização e elaboração de plano de cursos e oficinas voltados para capacitar funcionários e usuários em novos conhecimentos, que favoreçam um mergulho em uma nova atividade ou a ampliação de seus conhecimentos para desenvolver seus trabalhos diários e disponibilizar serviços com melhor qualidade;

Participação em comissões que envolvem análise de livros a serem aplicados nas escolas; políticas públicas voltadas para bibliotecas, livros, leitura e literatura;

Participação na elaboração do projeto A Escola vai à FCJA;

Participação na elaboração do projeto Cinema e Escola, entre outros. (Respondente 6)

Desde o acolhimento inicial mediando equipes, turistas, escolas e outros. Apresentação do museu, do mausoléu, dos arquivos e bibliotecas, com utilização de fotos e vídeos na autorização dos componentes. (Respondente 7)
Atualização de redes sociais com informações sobre projetos da instituição, além da atualização das obras do site do Memorial Ricardo Coutinho lá é possível, por exemplo, saber: data, local, valor e beneficiados em cada obra. (Respondente 2)

Fonte: Dados da pesquisa.

Ainda sobre as necessidades específicas dos pesquisadores, o Respondente 7 mencionou que existe um "acolhimento" aos turistas e ao público escolar. Isso indica que até uma atividade direta pode se diferenciar em relação ao apoio aos distintos públicos, já que a visita aos pesquisadores é diferente da que é direcionada aos estudantes pela diferenciação dos processos de formação. Assim, o mediador deve planejar estrategicamente cada atividade direta de mediação da informação.

Sobre o planejamento de ações de mediação da informação, o Respondente 6, ao citar as ações indiretas de mediação que realiza, exemplifica a idealização e a realização de plano de cursos e oficinas voltados a capacitação de funcionários e usuários, além da elaboração de projetos diversos. Observa-se que as ações indiretas estão inter-relacionadas às ações diretas de mediação da informação. Porém, uma é o processo basilar para a realização da outra, ao passo que ambas se ressignificam porque só com o desenvolvimento de ações diretas é que os usuários podem avaliar o planejamento e a organização dessas ações e interferir nelas.

Além dessas ações de planejamento, o Respondente 8 citou a realização de ações técnicas, como atividades indiretas de mediação da informação, 
análise, separação e identificação das espécies e tipologias documentais e higienização do acervo. Essas ações podem ser reconhecidas dentre as tradicionais e fundamentais do processo de mediação, porque, sem essas atividades, dificilmente os usuários poderiam recuperar, acessar e usar as informações de maneira rápida e ter um retorno específico de suas demandas.

Por fim, o Respondente 2 cita ações realizadas no âmbito das tecnologias digitais, como, por exemplo, a atualização dos conteúdos nas redes sociais. Essa ação indireta da mediação da informação e a visita aos ambientes físicos das unidades de informação favorecem a visibilidade desses espaços, dos seus produtos e serviços e dos valores culturais que estão interligados a esses dispositivos. Assim, para além do âmbito local e regional, tais ações podem ter mais repercussão e atrair usuários que ultrapassam as fronteiras geográficas.

Quando questionados sobre a realização de atividades que favorecem o reconhecimento e o fortalecimento da identidade e da memória do povo paraibano, uma quantidade significativa dos respondentes (7) afirmou que suas ações contribuem para a constituição da memória e da identidade dos paraibanos. Isso porque visibilizam dispositivos e elementos que representam o contexto sociocultural da região com ações conscientes de mediação da informação e da cultura. No Quadro 5, citam-se alguns exemplos de ações de mediação da informação e da cultura que foram extraídos das falas de alguns dos respondentes que apresentam, em suas atividades, a interferência no fortalecimento dos traços identitários e memorialísticos do povo nordestino.

Quadro 5 - Percepções dos respondentes sobre os elementos identitários e memorialísticos presentes em suas ações mediadoras

\begin{tabular}{|l|l|}
\hline Respondentes & \multicolumn{1}{c|}{ Comentários } \\
\hline Respondente 3 & $\begin{array}{l}\text { Sim, na apresentação dos acervos, mostramos as obras e o período que } \\
\text { cada titular/governador atuou no Estado, o ganho que a Paraíba teve } \\
\text { naquele período. Como também buscamos mostrar, principalmente para o } \\
\text { turista, que a riqueza cultural da Paraíba está presente do litoral ao alto } \\
\text { sertão, desde sua geografia e clima, como seus artistas locais. }\end{array}$ \\
\hline Respondente 4 & $\begin{array}{l}\text { Sim, o acervo da biblioteca tem uma quantidade considerável de livros } \\
\text { escritos e editados por autores e editoras paraibanas. Em 2012, nós } \\
\text { elaboramos um projeto para a formação de um acervo de literatura de } \\
\text { cordel. Depois de sua aprovação pelo órgão financiador, nós fizemos a } \\
\text { aquisição de cerca de 3.500 folhetos de literatura de cordel e organizamos }\end{array}$ \\
\hline
\end{tabular}




\begin{tabular}{|c|c|}
\hline & $\begin{array}{l}\text { em } 27 \text { classes temáticas, além de comprarmos o equipamento para } \\
\text { guardarmos de forma adequada. }\end{array}$ \\
\hline Respondente 6 & $\begin{array}{l}\text { Sim. A idealização e execução de projetos, como: } \\
\text { - Projeto de iniciação do acervo de Literatura de Cordel, intitulado } \\
\text { Leandro Gomes de Barros. Hoje, transformado em Núcleo de Literatura } \\
\text { de Cordel Leandro Gomes de Barros, parte integrante do Centro de } \\
\text { Literatura de Cordel e de Fazeres e Saberes populares do Estado da } \\
\text { Paraíba, projeto da Biblioteca aprovado pela FCJA e pelo Governo do } \\
\text { Estado da Paraíba; } \\
\text { - Projeto de idealização do "Dia Nacional do Escritor", homenageando os } \\
\text { escritores, através da escolha de um escritor paraibano para a homenagem. } \\
\text { Já foram homenageando: José Américo de Almeida, Manoel Monteiro, } \\
\text { Neide Medeiros dos Santos; } \\
\text { - Projeto de criação do selo comemorativo Leandro Gomes de Barros, no } \\
\text { ano do centenário de sua morte, com o seu lançamento no evento } \\
\text { intitulado: "Leandro Gomes de Barros: pioneirismo e genialidade"; } \\
\text { - Projeto de programação cultural do "Dia Nacional do Cordel", no ano } \\
\text { em que a Literatura de Cordel se tornou Patrimônio Cultural Brasileiro; } \\
\text { - Projeto de programação cultural "Emoções pelas Letras", com o } \\
\text { objetivo de incentivar o envolvimento das pessoas na literatura e nas artes } \\
\text { afins através de uma programação que provoque o encantamento e } \\
\text { despertem a emoção de todos os participantes e as habilidades. }\end{array}$ \\
\hline Respondente 7 & $\begin{array}{l}\text { Sim, pois a FCJA é um espaço aberto a grandes movimentações como os } \\
\text { eventos indígenas, palestras diversas sobre a difusão da cultura paraibana } \\
\text { e seus costumes, entre esses vários projetos À ESCOLA VAI A } \\
\text { FUNDAÇÃO, PROJETO LITERÁRIO, trazendo memórias desde o } \\
\text { tempo de vida do patrono até a geração atual, mostrando a evolução } \\
\text { histórica paraibana. }\end{array}$ \\
\hline Respondente 9 & $\begin{array}{l}\text { Sim. Atuo como mediadora nas visitas guiadas ao público em geral, a } \\
\text { estudantes da área de História, Arquivologia, Administração e de escolas } \\
\text { paraibanas aos arquivos da Fundação. Portanto, estamos difundindo esses } \\
\text { acervos, mostrando o valor desses arquivos, contribuindo e estimulando a } \\
\text { importância desse sentimento de pertença, desse centro de informação e de } \\
\text { memória que é a Fundação Casa de José Américo, os Arquivos de pessoas } \\
\text { que governaram a Paraíba e personalidades paraibanas que contribuíram } \\
\text { para o desenvolvimento do } \\
\text { nosso estado. } \\
\text { Através do projeto "A Escola vai à Fundação", atuamos também como } \\
\text { mediadores culturais e patrimoniais. Crianças e jovens de escolas } \\
\text { estaduais exercitam a cidadania, conhecendo um pouco da história política } \\
\text { da Paraíba e reconhecendo-se inserida nela, conscientizamos esse público } \\
\text { da importância valiosa do tesouro documental que são os arquivos. Na } \\
\text { finalização de cada etapa desse projeto há uma culminância, um evento } \\
\text { onde eles voltam à Fundação e expõem atividades culturais surgidas a } \\
\text { partir dessas visitas e das percepções que ficaram gravadas dessa } \\
\text { experiência, dessa memória individual e coletiva desses alunos } \\
\text { paraibanos. } \\
\text { Portanto, acredita-se que "os grupos sociais trazem uma mudança } \\
\text { profunda na relação tradicional com o passado. E esse comportamento está } \\
\text { interligado com sentimento de pertencimento a um dado grupo. Ou seja, as } \\
\text { relações de identidade de um indivíduo perpassam o seu contexto histórico } \\
\text { e, pode ser apresentado através das suas ações" (Nora, 1993). Nesse } \\
\text { sentido, contribuímos na formação de cidadãos atuantes e protagonistas de } \\
\text { sua história pessoal e de participantes ativos como cidadãos pertencentes, }\end{array}$ \\
\hline
\end{tabular}


Fonte: Dados da pesquisa.

Convém enfatizar que é sobremaneira importante que o agente mediador que atua em uma unidade de informação, como centros de documentação, arquivos, bibliotecas e museus, tenha consciência de que a memória é um elemento constituinte do sentimento de identidade individual e/ou coletiva, como refere Pollak (1992). Além disso, ele deve agregar às suas ações estratégias para mediar os referenciais de memória.

No que diz respeito à formação continuada, quando questionados sobre a busca por qualificação profissional (cursos, oficinas etc.) para aprimorar suas ações de mediação da cultura e da informação, os nove respondentes afirmaram positivamente e disseram como são motivados a se qualificar. Nessa questão, eles poderiam indicar mais de uma alternativa. Oito declararam que buscam qualificação de modo espontâneo; e cinco participam, inclusive, da qualificação promovida pela Fundação Casa de José Américo.

Quadro 6 - Exemplos de alternativas de formação continuada dos profissionais da informação

\begin{tabular}{|l|l|}
\hline Respondente 5 & $\begin{array}{l}\text { Sim. Participando de eventos nas áreas de História e Arquivologia, locais, } \\
\text { regionais e nacionais e de grupos de estudo. }\end{array}$ \\
\hline Respondente 8 & $\begin{array}{l}\text { Participando de cursos realizados pela ESPEP na própria Fundação Casa de } \\
\text { José Américo. E participando também de seminários técnicos e oficinas } \\
\text { realizadas em outras instituições. }\end{array}$ \\
\hline
\end{tabular}

Fonte: Dados da pesquisa.

Como demonstrado no Quadro 6, o Respondente 5 indica como realiza, de maneira espontânea, sua qualificação, e o Respondente 8 cita tanto uma busca espontânea quanto promovida pela própria Instituição.

De acordo com os resultados, quanto aos elementos que integram o conceito formulado por Almeida Júnior (2015), constatou-se que a maioria dos participantes desta pesquisa se reconhece como mediador da informação, desenvolve ações diretas e indiretas de maneira consciente e interfere no processo de mediação cultural, quando favorece o reconhecimento e o fortalecimento dos traços memorialísticos e identitários do povo paraibano. 


\section{Conclusão}

Os resultados desta pesquisa evidenciaram que as ações realizadas pelos agentes mediadores da Fundação Casa de José Américo estão em consonância com o conceito de mediação da informação, cunhado por Almeida Júnior (2015), e têm contribuído para fomentar a mediação cultural e promover o fortalecimento identitário e memorialístico do povo paraibano. As ações de mediação da cultura e da informação são essenciais para formar os usuários e atender às suas demandas e para constituir a memória e a identidade de um povo, pois, como sustenta Dodebei (1997), o sujeito necessita utilizar o passado como marco referencial e autoidentificador, e os aspectos memorialísticos são essenciais para o sentido de continuidade.

Considerando, ainda, o conceito defendido por Almeida Júnior (2015), identificou-se uma busca por atender tanto aos anseios individuais e singulares dos usuários quanto às necessidades plurais e coletivas da comunidade. $\mathrm{O}$ estudo mostrou que, para atingir esse objetivo, os agentes mediadores têm alcançado, por meio da formação continuada e da autoavaliação, um processo de conscientização e ressignificação de suas atividades mediadoras. Além disso, a ambiência e o repertório informacional das unidades de informação que integram a Fundação Casa de José Américo têm proporcionado uma ação protagonista por parte dos mediadores e dos usuários, quando se apropriam da informação e desses ambientes informacionais.

Com base nos resultados alcançados, sugere-se que, além de identificar e considerar os elementos que integram o conceito formulado por Almeida Júnior (2015), os mediadores da informação devem (re)conhecer as manifestações culturais que estão no entorno dos ambientes informacionais e que esses elementos são singulares e próprios dos ambientes e dos grupos. Se os mediadores da informação atuarem em uma perspectiva consciente para que os sujeitos reconheçam nos centros de documentação, nos arquivos de nas bibliotecas e/ou nos museus, aspectos identitários e memorialísticos poderão fortalecer os laços entre esses ambientes informacionais e os sujeitos. 


\section{Referências}

ALMEIDA JÚNIOR, O. F. Mediação da informação: um conceito atualizado. In: BORTOLIN, S.; SANTOS NETO, J. A.; SILVA, R. J. (org.). Mediação oral da informação e da leitura. Londrina: Abecin, 2015.

ALVES, Magda. Como escrever teses e monografias. Rio de Janeiro: Elsevier, 2007.

AZEVEDO NETTO, C. X. Informações e memória: as relações na pesquisa. Revista História em Reflexão, Dourados, v. 1, n. 2, 2007.

BARDIN, L. Análise de conteúdo. São Paulo: Edições 70, 2011.

DODEBEI, V. L. D. O sentido e o significado de documento para Memória Social. 1997. Tese (Doutorado em Comunicação) - Universidade Federal do Rio de Janeiro, Rio de Janeiro, 1997.

FUNDAÇÃO CASA DE JOSÉ AMÉRICO. Quem somos. [20--?]. Disponível em: https://fcja.pb.gov.br/o-que-e-a-fundacao. Acesso em: 4 abr. 2020.

GIL, A. C. Como elaborar projetos de pesquisa. São Paulo: Atlas, 2010.

GOMES, H. F. Comunicação e informação: relações dúbias, complexas e intrínsecas. In: MORIGI, V.; JACKS, N.; GOLIN, C. (org.). Epistemologias, comunicação e informação. Porto Alegre: Sulina, 2016.

GOMES, H. F. Mediação da informação e protagonismo social: relações com vida ativa e ação comunicativa à luz de Hannah Arendt e Jürgen Habermas. In: GOMES, H. F.; NOVO, H. F. (org.). Informação e protagonismo social. Salvador: EDUFBA, 2017.

GOMES, H. F. A dimensão dialógica, estética, formativa e ética da mediação da informação. Informação \& Informação, Londrina, v. 19, n. 2, 2014.

GONÇALVES, J. R. S. Ressonância, materialidade e subjetividade: as culturas como patrimônios. Horizontes Antropológicos, Porto Alegre, ano 11, n. 23, 2005.

LIMA, C. B.; PERROTTI, E. O Bibliotecário como mediador cultural. In:

ENCONTRO NACIONAL DE PESQUISA EM CIÊNCIA DA

INFORMAÇÃO, 18., 2017, Marília. Anais [...]. Marília: UNESP, 2017.

NOGUEIRA, A. G. R.; RAMOS FILHO, V. S. Afinal, o que é patrimônio?

Conceitos e suas trajetórias. Fortaleza: Fundação Demócrito Rocha, 2020.

PAES, M. L. Arquivo: teoria e prática. 3. ed. Rio de Janeiro: FGV, 2009. 
PIERUCCINI, I. Ordem informacional dialógica: mediação como apropriação da informação. In: ENCONTRO NACIONAL DE PESQUISA EM CIÊNCIA DA INFORMAÇÃO, 8., 2007, Salvador. Anais [...]. Salvador: Universidade Federal da Bahia, 2007.

POLLAK, M. Memória e Identidade Social. Estudos Históricos, Rio de Janeiro, v. 5, n. 10, 1992.

SILVA, B. D.; SANTOS NETO, J. A. Práticas de mediação cultural nas bibliotecas públicas municipais de Londrina/PR. Biblionline, João Pessoa, n. 2, v. 13, 2017.

\title{
Mediation of culture and information at Fundação Casa de José Américo
}

\begin{abstract}
Cultural mediation and mediation of information promote the dissemination and appropriation of information that permeates the social sphere, favor access to memory and, at the same time, potencialize the recognition of feeling of belonging to places and social groups. In this context, this communication aimed to analyze the actions performed at Fundação Casa de José Américo, categorize them in the light of the concept mediation of information coined by Almeida Júnior and identify the evidence of cultural mediation that favors the identity and memorial strengthening of the Paraíba people. The theoretical and empirical reference were based on the conceptual aspects of cultural mediation, mediation of information, memory and identity. As for the methodology, the research, in which the case study method was used, is of a descriptive nature, and the object of investigation was Fundação Casa José Américo. To collect the data, it was adopted the questionnaire application technique with the professionals who work in the information section of the aforementioned Institution. After analyzing the collected data, it was found that most participants in this research recognize themselves as mediators of information, develop direct and indirect actions in a conscious way and have achieved interference in the process of cultural mediation, when they favor recognition and strengthening of the memorialistic and identity traits of the people of Paraíba.
\end{abstract}

Keywords: Cultural mediation. Mediation of information. Memory and identity.

Recebido: $16 / 05 / 2020$

Aceito: 04/11/2020 


\section{Declaração de autoria}

Concepção e elaboração do estudo: Ana Claudia Medeiros de Sousa, Raquel do Rosário Santos

Coleta de dados: Andréa Medeiros de Sousa Maia

Análise e discussão de dados: Ana Claudia Medeiros de Sousa, Raquel do

Rosário Santos

Redação e revisão do manuscrito: Ana Claudia Medeiros de Sousa, Raquel do Rosário Santos, Andréa Medeiros de Sousa Maia

\section{Como citar}

SOUSA, Ana Claudia Medeiros de; SANTOS, Raquel do Rosário; MAIA, Andrea Medeiros de Sousa. Mediação da cultura e da informação na Fundação Casa de José Américo. Em Questão, Porto Alegre, v. 27, n. 3, p. 68-93, 2021 doi: http://dx.doi.org/10.19132/1808-5245273.68-93 